Mini Review

\title{
Highly Enhanced Electrochemical Performance of Novel based Electrode Materials for Supercapacitor Applications - An Overview
}

Rasu Ramachandran ${ }^{3, *}$, Tse-Wei chen, ${ }^{1,2}$, Shen-Ming Chen ${ }^{1, *}$, Paulsamy Raja ${ }^{4}$, Carlos Fernandez, Selvarajan Divya Rani ${ }^{3}, \quad$ Pandi Gajendran ${ }^{3}$, Ganapathy Raju ${ }^{6}$, Thangaraj Baskar ${ }^{7}$, Tharini Jeyapragasam ${ }^{8}$

${ }^{1}$ Electroanalysis and Bioelectrochemistry Lab, Department of Chemical Engineering and Biotechnology, National Taipei University of Technology, No.1, Section 3, Chung-Hsiao East Road, Taipei 106, Taiwan, ROC.

${ }^{2}$ Research and Development Center for Smart Textile Technology, National Taipei University of Technology, Taipei 106, Taiwan, ROC.

${ }^{3}$ The Madura College, Department of Chemistry, Vidya Nagar, Madurai - 625 011, Tamil Nadu, India. ${ }^{4}$ Vivekananda College of Arts and Science, Agastheeswaram, Kanyakumari - 629 004, Tamil

Nadu, India.

${ }^{5}$ School of Pharmacy and Life Sciences, Robert Gordon University, Aberdeen (UK) - AB107GJ.

${ }^{6}$ Department of Zoology, Pioneer Kumaraswamy College, Nagercoil - 629 003, Tamil Nadu, India.

${ }^{7}$ School of Food and Biological Engineering, Jiangsu University, Zhenjiang -212013, Jiangsu province, P.R.China.

${ }^{8}$ Sethu Institute of Technology, Pulloor - 626 115, Kariapatti, Tamil Nadu, India.

Corresponding Authors:

*E-mail: smchen78@ms15.hinet.net (S.-M. Chen), ultraramji@ gmail.com (R. Ramachandran)

doi: $10.20964 / 2019.02 .75$

Received: 5 November 2018 / Accepted: 14 December 2018 / Published: 5 January 2019

The research and recent progress of electrochemical energy storage devices applied to various applications during the past two decayed are reviewed. Different electrode materials (carbon-based materials, metal oxides, conducting polymers, metal nanoparticles and nanocomposites), can be used as the most important features for supercapacitors. Recently, research efforts of supercapacitor electrodes have been used to increase the specific capacitance and its cyclic stability. In this review designate current efforts energy storage preparation methods, materials and different morphological structure for electrochemical capacitor applications. The principle of design, extended surface area, improve the capacitance properties and long-durability of the electrochemical capacitor are discussed.

Keywords: Nanocomposite, Morphology, Electrochemical properties, Ultracapacitors, Electrode stability. 


\section{FULL TEXT}

(C) 2019 The Authors. Published by ESG (www.electrochemsci.org). This article is an open access article distributed under the terms and conditions of the Creative Commons Attribution license (http://creativecommons.org/licenses/by/4.0/). 